\title{
Integrating Remote Sensing and GIS Techniques with Conventional Methods to Assess and Characterize Surface and Groundwater Resources of Tendaho Graben, Ethiopia
}

\author{
Taddesse M. Bollollo ${ }^{1,2 *}$, Nicola Perilli ${ }^{3}$ \\ ${ }^{1}$ Surveying, Geospatial and Civil Informatics Center, ECDSWC, Addis Ababa, Ethiopia \\ ${ }^{2}$ Ethiopian Institute of Water Resources, Addis Ababa University, Addis Ababa, Ethiopia \\ ${ }^{3}$ Civil and Industrial Engineering Department, Pisa University, Pisa, Italy \\ Email: ^taddmel@gmail.com, ^taddesse.melkamu@aau.edu.et, nicola.perilli@unipi.it
}

How to cite this paper: Bollollo, T.M. and Perilli, N. (2018) Integrating Remote Sensing and GIS Techniques with Conventional Methods to Assess and Characterize Surface and Groundwater Resources of Tendaho Graben, Ethiopia. International Journal of Geosciences, 9, 272-288.

https://doi.org/10.4236/ijg.2018.95017

Received: July 15, 2016

Accepted: May 18, 2018

Published: May 21, 2018

Copyright $\odot 2018$ by authors and Scientific Research Publishing Inc. This work is licensed under the Creative Commons Attribution International License (CC BY 4.0).

http://creativecommons.org/licenses/by/4.0/

\begin{abstract}
The study focused on water resource assessment through utilization of remote sensing, which is a powerful technique for the collection of multi-temporal synoptic data sets. Geographic Information System (GIS) has been also used for turning large volumes of spatial data into useful information by integrating spatial data such as topography, geology, precipitation, land cover, satellite images etc. for joint analysis. In this study Remote sensing techniques have offered useful information on regional geology, geomorphology, hydrology, soils and land use. Using Landsat $7 \mathrm{ETM}^{+}$path 167, row 52 drainage conditions, land use/cover, drainage patterns, lineaments and geomorphology (relief, morphology) analysis and interpretation have been made, all of which have influences on the movement and occurrence of groundwater. The interpretation of satellite data in conjunction with sufficient ground truth has made it possible to identify and outline various ground features that serve as direct or indirect indicators of the occurrence of groundwater. Different image processing techniques have been deployed to extract specific information for required analyses. Spatial filtering for tectonic structures identification, False Color Composite for identification of lithology, drainage etc. have been deployed. Through the spatial integration, it is observed that tectonic structures have controlled surface and sub surface water availability of the area. The present works in general have focused on the role of remote sensing and GIS techniques in surface and groundwater resources assessment with limited
\end{abstract}


application of conventional methods. Remote sensing has invaluable capability in groundwater and surface water assessment of an area like this Graben where there is accessibility problem and challenging hot climatic conditions which hinders ground investigations.

\section{Keywords}

Remote Sensing, GIS, Groundwater, Afar, Graben, Tectonics

\section{Introduction}

Remote sensing of the environment comprises the measurement and recording of electromagnetic energy reflected from or emitted by the earth's surface and atmosphere from a vantage point above the earth's surface and relating of such measurements to the nature and distribution of earth surface materials and atmospheric conditions [1]. This technique also offers useful information on regional geology, geomorphology, hydrology, soils and land use, all of which have influence on the movement and occurrence of groundwater [2]. The most successful method of integration of remote sensing data into GIS uses a grid square as a base and converts the remote sensing data into a geometrically corrected thematic map prior to integration with other data elements [3]. In this study water resources assessment of a central Afar Graben, Tendaho, was done through application of remote sensing, which is a powerful technique for the collection of multi-temporal synoptic data sets, and GIS methods.

\section{Materials and Methods}

The data and software used in this research work includes Landsat $\mathrm{ETM}^{+}$in digital format, Digital Elevation Model (DEM), NOAA satellite data, topographic map, Geological map of central and southern Afar, Hydrogeological map, Tabular data, ENVI 3.5, IDRISI 2.00, Arc view 3.2, ArcGIS 10, Cartalinx 1.04 etc. Integrated remote sensing, GIS and conventional techniques have been employed. Using satellite imagery the two types of interpretation elements: dynamic (season dependent) elements such as drainage conditions (natural, dry, moist, wet, irrigation), vegetation cover (characteristics, species, change with season) and land use (forestry, farming, grazing, etc.) and static or less season dependent elements such as drainage patterns (hydrology, lithology, topography), lineaments (faults, joints, fractures) and geomorphology (relief, morphology) were studied. Drainage, landforms, cover and lineaments analysis and interpretation were also performed. Various thematic maps such as geological, drainage, lineament, and land use/land cover and hydrogeological maps data sets in spatial format brought to GIS environment. Then, all the thematic layers were systematically integrated to derive different hydrological and hydrogeological conditions of the Graben. Different layers have been analyzed using GIS software 
which allows stacking of georeferenced data for comparison and integration and data query for sub setting the needed information.

\section{Study Area}

\subsection{Location, Hydrometeorology and Geomorphology}

Tendaho graben is located in the North Eastern part of Ethiopia at about $650 \mathrm{~km}$ from Addis Ababa in the Afar depression. It is a NW-SE trending Graben about $50 \mathrm{~km}$ wide and is the southern extension of the Afar active spreading Zones where the active Erta Ale-Manda Hararo volcanic ranges are situated. The Graben is accessible by the main Addis Ababa Djibouti asphalted road, all weather and dry season roads. The Graben is situated in arid climatic zone in which the general altitude is less than $1000 \mathrm{~m}$. According to the climatic classification of Ethiopia, it is considered to be a low land area characterized by hot and dry climatic condition almost throughout the year. According to moisture zone classification by UNEP, as cited in [4], obtained from rainfall PET ratio, the studied area has been categorized as Arid zone since the moisture index (MI) is between 0.05 and 0.2 (Table 1 ).

Awash River is the only perennial river in the area. On the lower plains the river enters a series of lakes and swamps such as Gamari, Adobed, Afambo and Abhedet (Abhe) where its waters are lost by evaporation. There are some intermittent rivers which flow for a very short period during the rainy time such as Logya River-the last major tributary to the river Awash.

The Graben is a wide NW-SE trending tectonic depression which extends from Manda Hararo ranges in the north to Lake Abhedet (Abhe) region in the south. The area has almost a flat landscape with insignificant altitude variation throughout the Graben except the presence of some volcanic peaks such as Dama'ale, Kurub, and Borawli which have $1063 \mathrm{~m}, 625 \mathrm{~m}$, and $875 \mathrm{~m}$ altitude above mean sea level respectively (Figure 1).

\subsection{Geology and Tectonics of Afar}

The Afar depression is the only place on the globe where well defined active rift systems join each other and oceanic crust is exposed at the surface [5] [6]. Physiographically, it is very clearly defined, being bounded from south and west by upland regions: the Ethiopian plateau to the south, Danakil and Aisha horsts to the northeast and east respectively [7].

Table 1. Moisture zones classification based on the desertification convention (UNEP, 1992).

\begin{tabular}{cccccccc}
\hline Station & Lat (deg) & Long $(\mathrm{deg})$ & Elev $(\mathrm{m})$ & Rainfall $(\mathrm{mm})$ & Pet & Mi & Zone \\
\hline Tendaho & 11.42 & 40.57 & 400 & 207 & 2608 & 0.08 & A \\
Aysaita & 10.34 & 41.27 & 430 & 164 & 2950 & 0.06 & A \\
Dubti & 11.44 & 41.05 & 376 & 209 & 2471 & 0.08 & A \\
Manda & 12.24 & 42.11 & 670 & 28 & 2833 & 0.01 & HA \\
\hline
\end{tabular}

A = Arid, HA = Hyper Arid. 

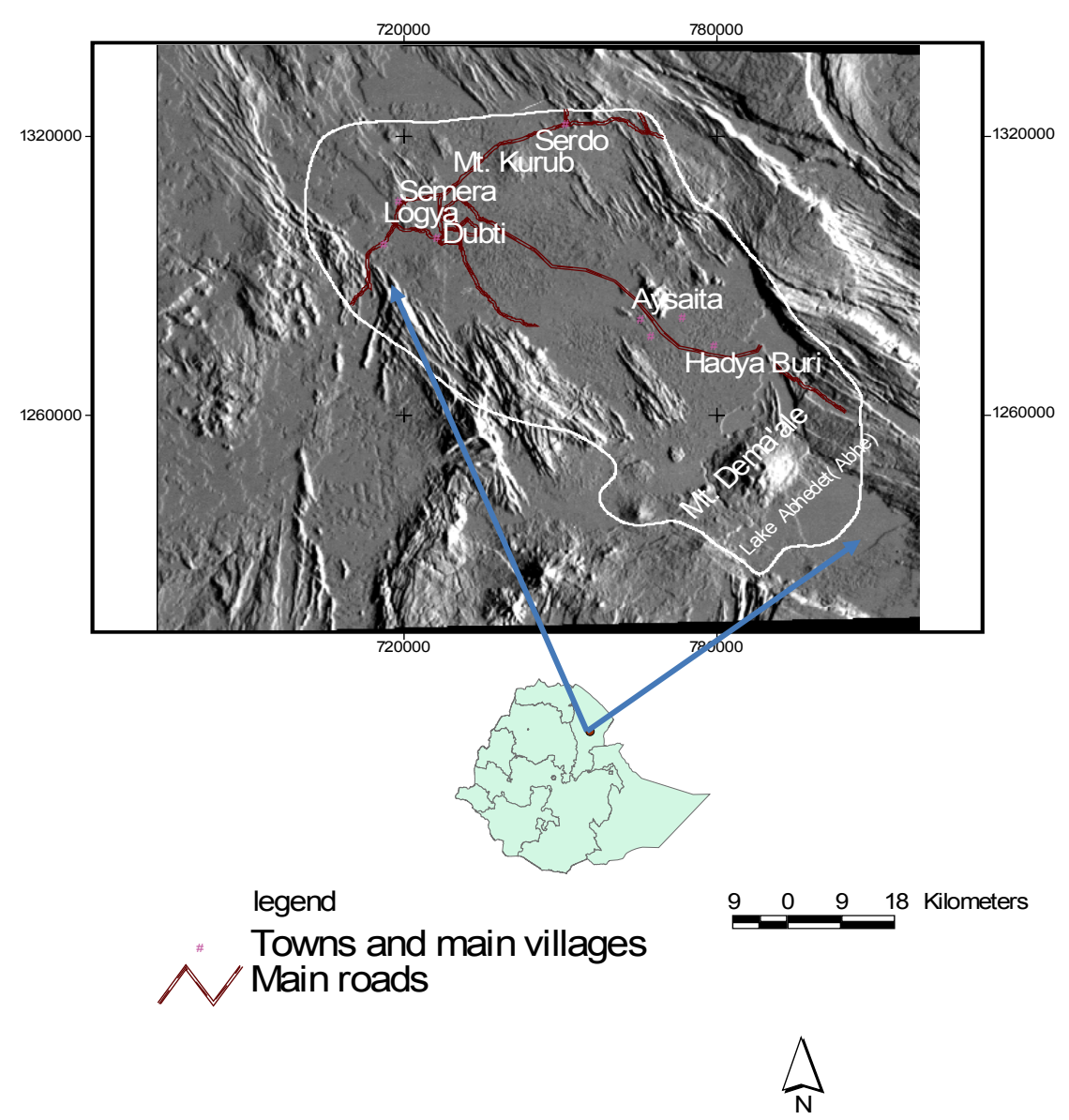

Figure 1. Location of the study area and digital elevation model.

The Main Ethiopian Rift is truncated by this Graben (Figure 2). The Graben by itself trends NW-SE. The present day separation of Nubian and Arabian plates takes place along this Graben [8]. The borders of the Tendaho rift are constituted by the Afar stratoid series, the rift is filled with lacustrine and alluvial deposits and with post stratoid basalt flows. This filling is at some places topped by recent volcanoes. Evidence for active NW striking fault is present in the sediments within the Dubti plantation. They have aligned steaming grounds, fumaroles and hydrothermal deposits [9].

\subsection{Land Use/Land Cover (LULC)}

Irrigated Agricultural practice using Awash River is very common in the Graben especially in Dubti, Aysaita and Detbahri area. The main crops of the area are maize and cotton. Even though cotton plantation is the major practice in the area maize and fruits cultivation are also important agricultural practices. Seasonal grasses and scrubs characterize the area. Relatively dense vegetation is found only along the Awash River and wetlands due to better moisture conditions. From Tendaho (Logya) to Aysaita Tamarix Aphyla (locally segentu) and Acacia Abysinica (Keseltu) are dominant. Tamarix Aphyla which is usually used as construction material locally is the most dominant in this part of the studied 


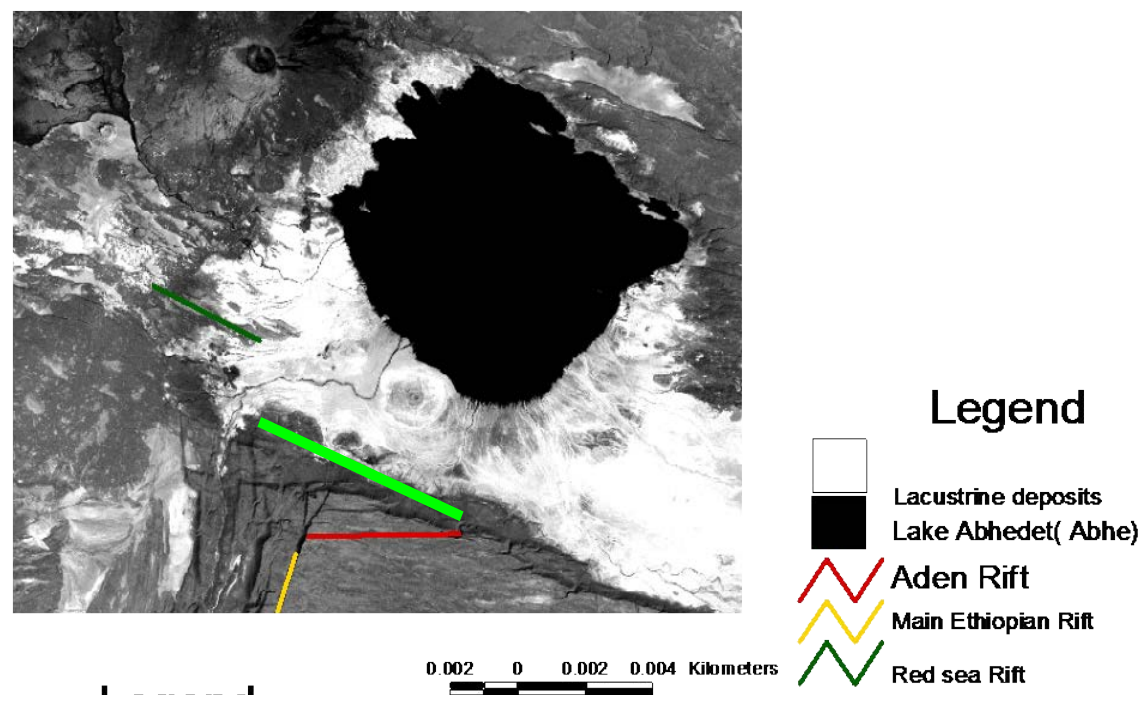

Figure 2. One of the interaction zone of Red Sea, Aden and Ethiopian main rift near Lake Abhedet (Abhe).

area. From Aysaita towards the Awash terminal and its environs Acacia Abysinica, which is used for shed, fodder during drought season and also traditional medicine, is a dominant vegetation cover, though there are other species like Acacia nilotica, Acacia mearnsii, Acacia bussei and Acacia asale.

\section{Result and Discussion}

\subsection{Pre-Processing}

When image data is recorded by sensors on satellites errors in geometry and in the measured brightness values of the pixels (radiometric errors) occurred due to the effect of instrumentation and/or the atmosphere, the rotation of the earth during image acquisition, variations in platform altitude, attitude and velocity etc. Before conducing further processing and analysis pre-processing was done to enhance the quality of the image data by reducing or eliminating radiometric (such as bad lines) and geometric errors using ENVI software facility.

\subsection{Digital Image Processing}

\subsubsection{Image Registration (Georeferencing) and Band Selection}

Image registration uses the technique of coordinate transformation. It could be absolute (Image to map) and relative (Image to image). In this study absolute image registration in which registration of Landsat $\mathrm{ETM}^{+}$image on to a topographic map of the area was applied.

Digital satellite data of the area obtained from the Landsat $7 \mathrm{ETM}^{+}$in path-167 and Row-52. The nine bands, two of them are thermal bands, were treated for different applications of the study. The variance of a single variable expresses the spread of its values about the mean. Covariance is a measure of the joint variation of two variables. Positive covariance indicates positive correlation and negative values shows inverse relationship. If the covariance value is zero the 
two bands are completely independent of each other and therefore provides good result in different multispectral analysis.

The co variances between any two of the six bands show positive correlations which exemplify the high redundancy of information. Bands 3, 4, 5 and 7 have relatively lower correlation (Table 2).

\subsubsection{Principal Component Analysis/Karhunen-Loeve Transform}

Principal Component Analysis (PCA) is a statistical form of data compression techniques for the transformation of multispectral images to replace the original wavebands with new orthogonal axes that better describe the particular scene under study. It is a means of improving the spread of data by redistributing them about new axes to increase separation of difference in the data [1] [3] [10]. In this study the information content of the bands compressed into three transformed PCA images. Data redundancy (strong correlation) between the wave bands which are close to one another in any part of the Electro Magnetic Spectrum has been solved through principal component analysis. Each Eigen vector is a loading factor for the contribution of individual band to a principal component (Table 3).

The first principal component contains much of the information. In this study the first principal component contains $88.83 \%$ of the total variance (Table 4 ).

Table 2. Eigen vectors and principal components of the six bands.

\begin{tabular}{lllllll}
\hline Bands & Band 1 & Band 2 & Band 3 & Band 4 & Band 5 & Band 7 \\
\hline Band 1 & 4478.57 & & & & & \\
Band 2 & 4364.94 & 4367.14 & & & & \\
Band 3 & 2059.65 & 2063.04 & 1028.87 & & & \\
Band 4 & 2991.37 & 3127.78 & 1468.64 & 3973.27 & & \\
Band 5 & 3310.59 & 3368.08 & 1674.03 & 3064.54 & 3402.92 & \\
Band 7 & 3600.33 & 3602.05 & 1794.67 & 2747.34 & 3414.58 & 3678.82 \\
\hline
\end{tabular}

Table 3. Eigen vectors and principal components of the six bands.

\begin{tabular}{ccccccc}
\hline COMPONENT & $\mathbf{1}$ & $\mathbf{2 2}$ & $\mathbf{3}$ & $\mathbf{4}$ & $\mathbf{5}$ & $\mathbf{6}$ \\
\hline Eigvec 1 & 0.414465 & -0.330866 & -0.367177 & -0.503514 & -0.0073249 & -0.570118 \\
Eigvec 2 & 0.421291 & -0.239530 & -0.342863 & -0.112893 & -0.141895 & 0.784032 \\
Eigvec 3 & 0.420983 & -0.264230 & -0.103971 & 0.829019 & 0.087946 & -0.217115 \\
Eigvec 4 & 0.360197 & 0.837864 & -0.337053 & 0.829019 & 0.087946 & -0.217115 \\
Eigvec 5 & 0.414867 & 0.222665 & 0.519666 & -0.014435 & -0.710386 & -0.058288 \\
Eigvec 6 & 0.414307 & -0.108354 & 0.594271 & -0.214959 & 0.639785 & 0.088990 \\
\hline
\end{tabular}

Table 4. Eigen values calculated from the six bands.

\begin{tabular}{ccccccc}
\hline COMPONENT & PC 1 & PC 2 & PC 3 & PC 4 & PC 5 & PC 6 \\
\hline \% variation & 88.83 & 6.75 & 3.47 & 0.59 & 0.21 & 0.15 \\
Eigen Values & 5.33 & 0.40 & 0.21 & 0.04 & 0.01 & 0.01 \\
\hline
\end{tabular}




\subsubsection{Band Rationing}

The ratio of one band to another which involves division of the $\mathrm{DN}$ value of each pixel in one band by the other band produce new pixel values ranging from Zero to infinity. It is an essential process applied to reduce the effects of topographic conditions, shadows, seasonal changes in sunlight illumination angle and intensity.

It suppresses brightness variations due to topographic relief and enhances subtle spectral variation. Ratio images are useful in lithological mapping since they directly exaggerate subtle color differences among the different rocks exposed on the surface [11].

Large parts of the Tendaho Graben floor are flat horizontal surface so that the sun illuminates homogeneously and the problem of $\mathrm{DN}$ value variation across a scene of uniform reflectance properties is minimal. But the boarders of the Graben show some difference in illumination properties due to the topographic variation. The ratio between Band 7 and Band 3 shows good color contrast among basalts and other materials (Figure 3 ).

NDVI is also one of the rationing techniques. Ratio between Band 3 and Band 4 applied also to further enhance the difference between rocks. The high ratio values (white) indicate the absence and low ratio (black to dark grey shades)
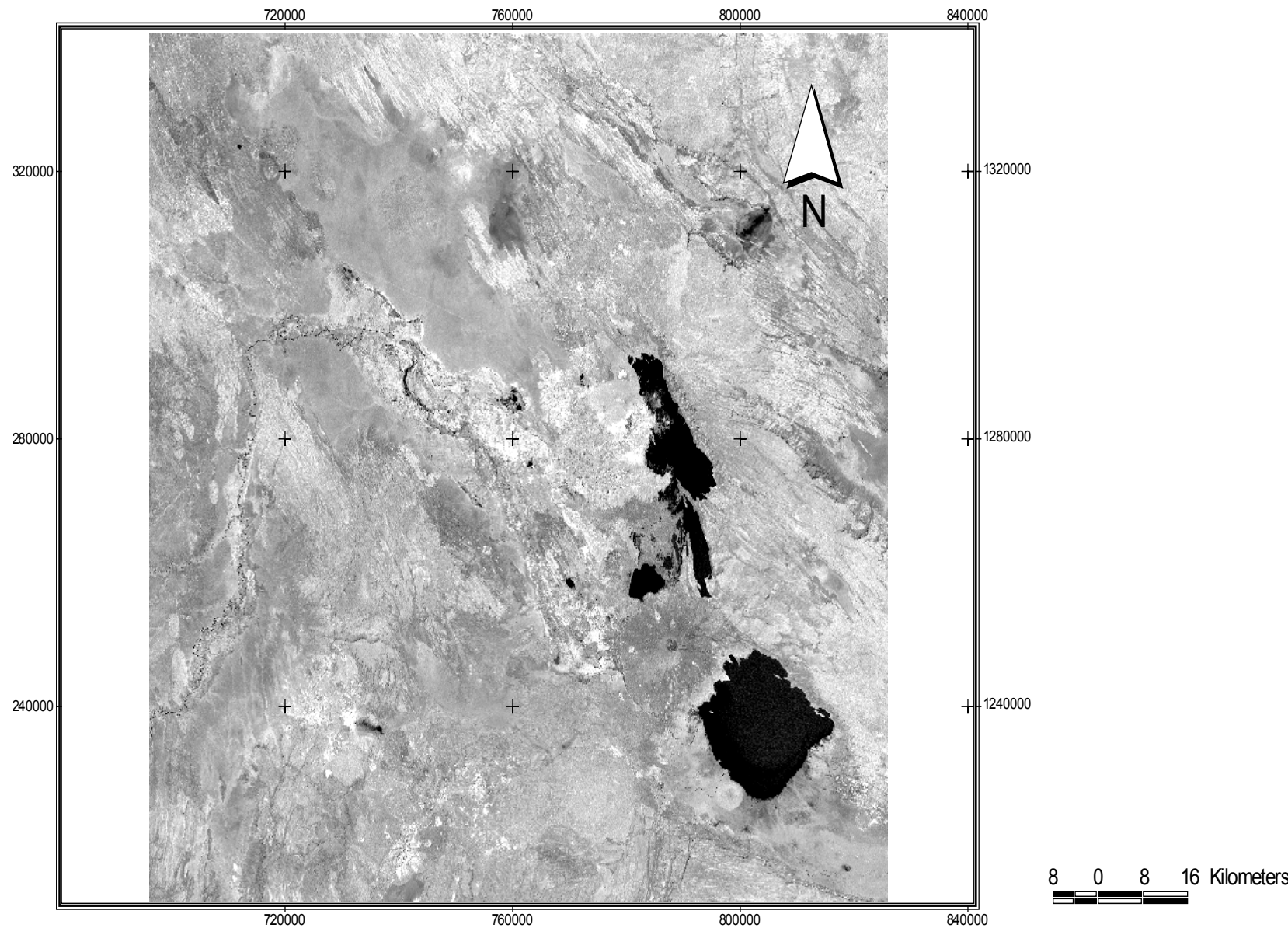

Figure 3. Image of ratio between Band 7 and Band 3 (Extracted from the rectified image of the path-167 and row-52 scene). 
presence of vegetations. Vegetation is better captured in Band 5 than Band 1. Therefore the high ratio values between Band 5 and Band 1 shows the presence of limonite or vegetation. Identifications of vegetation cover in the Graben used to understand groundwater conditions of the area.

\subsubsection{Color Composition}

Color composition is important to increase sensitivity of human eyes in interpreting images. It has the possibility of collective multi-image display and interpretation. A False Color Composite image using Bands 7, 4 and 1 (RGB) is usually used for earth resource applications. In this image water appears as shades of blue, vegetation as green, and dry land as red, brown and black tones. Highly reflective areas, such as clouds, appear bright and non-reflective areas such as dry rocks and heavily shadowed areas appear black (Figure 4). All the vegetation cover, lithology and water bodies are clearly observed in this composite image. In this study the true color composite (Bands 1, 2 and 3) have been utilized to discriminate vegetation and water bodies which have much importance in water resources condition of the study area.

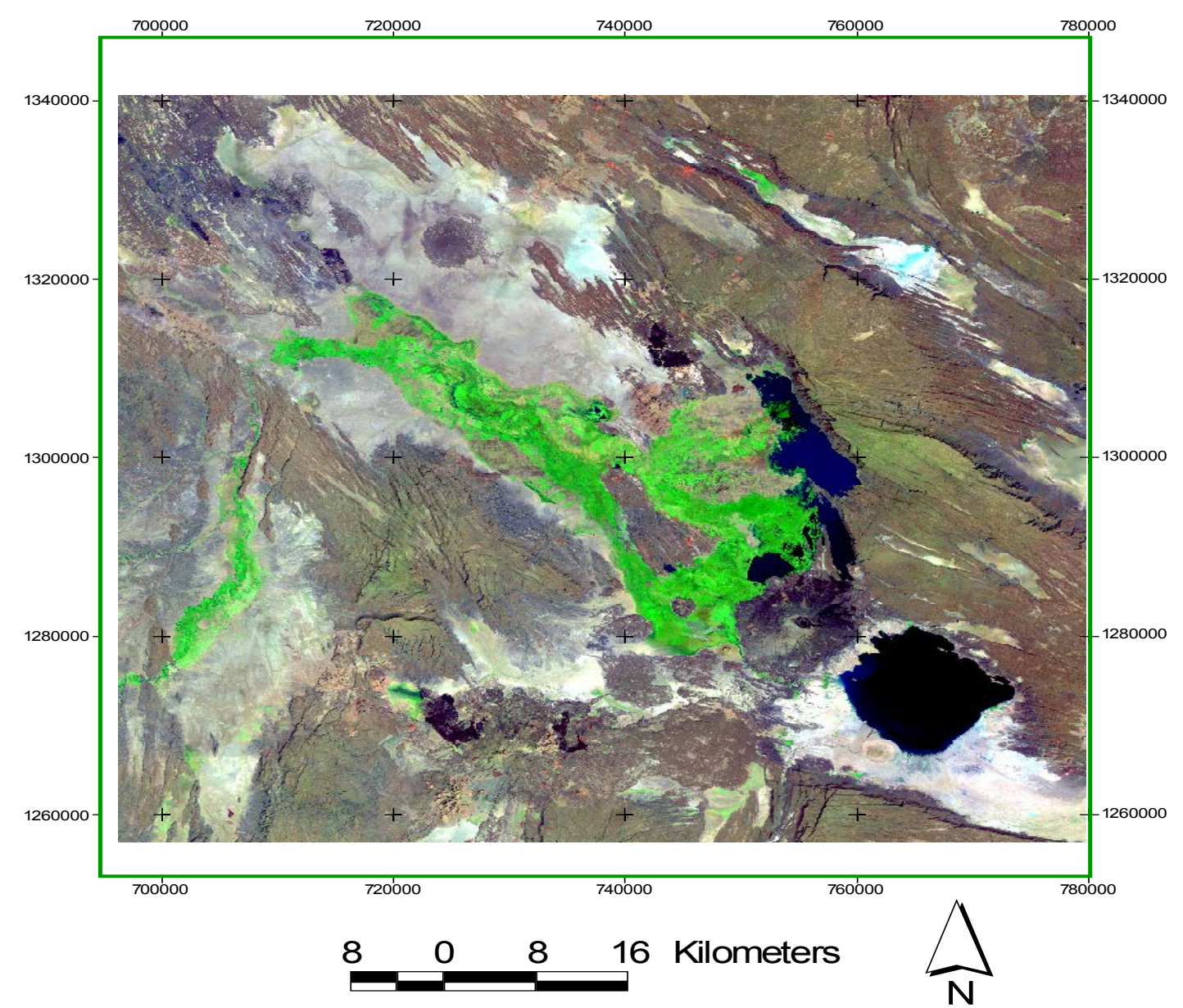

Figure 4. False color composite (FCC) of bands 7, 4 and 2 in RGB order. (The green color shows vegetation at left and right bank of Awash River and swampy area. Deep blue color in the lake Gamari shows the shallow depth of the lake. The grayish and whitish portions are alluvial and lacustrine deposits.) 


\subsubsection{Spatial Filtering}

Spatial frequency is the number of changes in brightness value per unit distance for any particular part of an image. Filtering suppress certain frequencies and passing (emphasizing) of the other. The digital spatial filtering technique applied in image space and gives equal weight to every pixel within the filter window or kernel. The kernel size is determined by the required size of the linear feature. The high pass filtering enhances high frequency variations. Faults, joints etc are enhanced with directional filters. This directional filtering technique identifies tectonic structures of the Graben which dominantly trends NW-SE directions. Non directional filtering (edge enhancement) enhanced edges of all direction and used to map lithology of the area. The dominant NW-SE structures of the Graben have been enhanced using the following kernel.

The study area is situated in arid area with clearly visible geological features. The tectonic structures can be visible easily even without applying further enhancement. Kernels can be of just about any size. $3 \times 3$ filter is a default minimum kernel size. Therefore in this study a $3 \times 3$ kernel was used for simplicity.

The dominant NW-SE trending tectonic structures are enhanced by the application of filtering Kernel (Figure 5). These structures are important structures in the hydrological and hydrogeological characteristics of the Tendaho Graben. The image shows the southern extension of the active Erta'ale volcanic range. This range includes a fault zone that reaches across the Awsa plains to the Goba'ad trough, south east of Lake Abhedet in addition to the Manda Hararo [6].

Directional filtering applied to the image to unravel geological structures and simplify structural mapping in the Graben where NW-SW trending geological structures are dominant (Figure 6).

\subsection{Interpretation of Satellite Data}

From Landsat Enhanced Thematic Mapper plus image of the Graben it is derived that Lake Gamari and parts of Lake Afambo shows grayish color and Lake Abhedet (Abhe) shows dark color which is related to spectral reflectance characteristics of the water. The floor of the Graben is grey to white tone which indicates the high reflection characteristics of the alluvial sediments. The black appearance of the lakes in the visible portion (wavelengths less than about 0.6 $\mu \mathrm{m})$ is due to depth of the lakes or clearness of the lake water. The reflectance of clear water is higher than turbid water. Some of the lakes show higher visible reflectance due to accumulation of suspended sediments transported to the lakes. It is also shown that at the periphery of Lake Gamari the reflectance of the

$\begin{array}{cccccc}0 & 0 & 0 & 0 & -1 & 0 \\ 0 & 1 & 0 & -1 & 4 & -1 \\ -1 & 0 & 0 & 0 & -1 & 0\end{array}$

(a)

(b)

Figure 5. $3 \times 3$ filtering kernels used to enhance the image. (a) Directional (anisotropic); (b) Non directional (isotropic). 


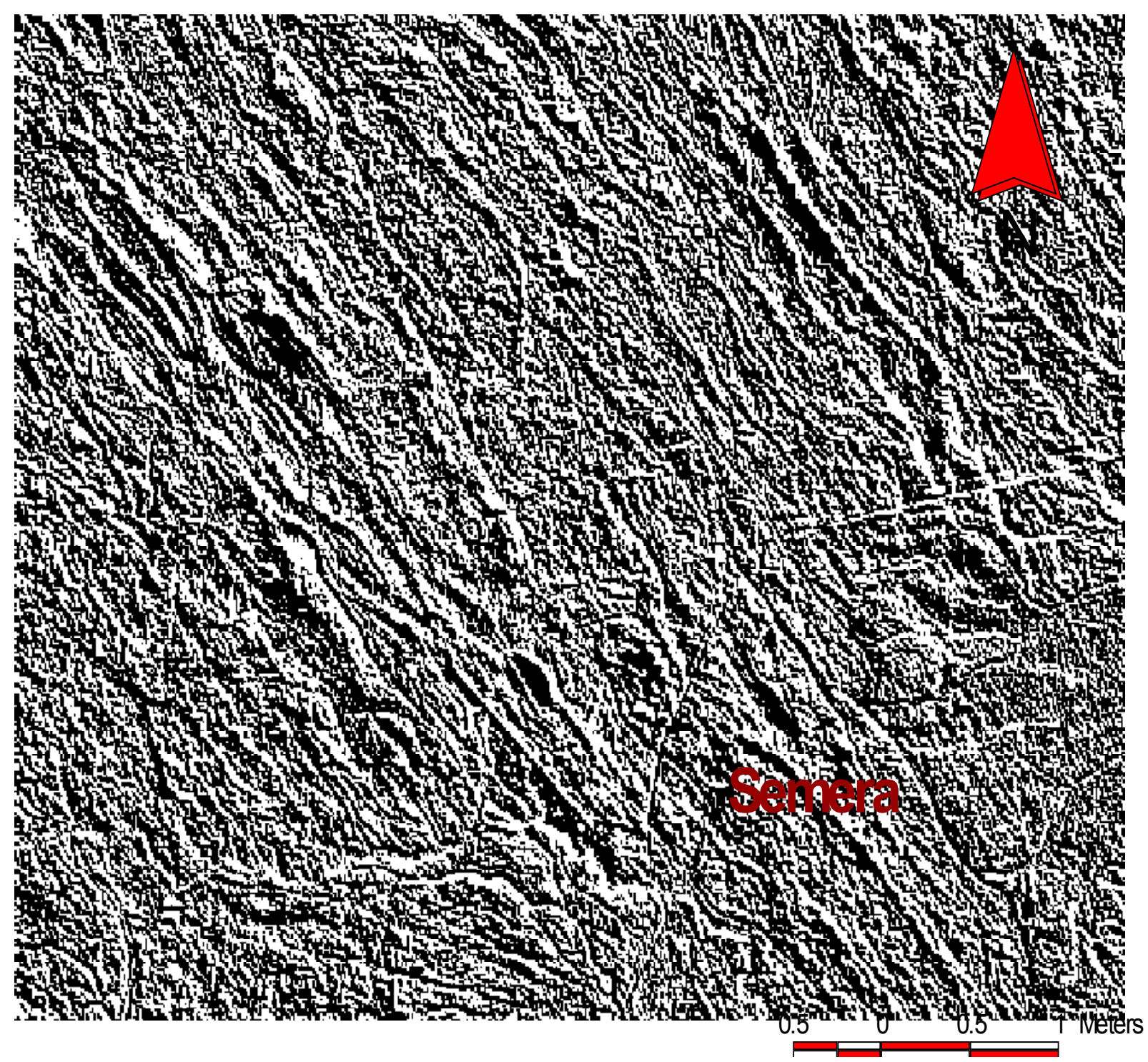

Figure 6. Filtered image by kernel value shows NW-SW trending tectonics.

water changes due to the concentration of algae. The water reflectance decreases in blue wavelengths and increases in green wavelengths. The reflectance from the water body therefore can be either from its surface, materials suspended in the water or with the bottom of the water body. Geological interpretation of Landsat image of the area shows that most of the floor of the Graben is alluvial sediments with some scattered basaltic lava flows. The recent deposits of this area usually comprised of clay, silt and some lacustrine deposits which are recognized by its light tone character. Rhyolite is mostly found in the north, north eastern and eastern border of the Graben and the rest of the Graben borders are dominated by basaltic rocks. Basalt and andesite which form the outcrops shows dark to intermediate tone. Mount Dama'ale, Kurub and Borawli are recent volcano with associated lava flows (Figure 7). These could be easily characterized by their flow pattern. 


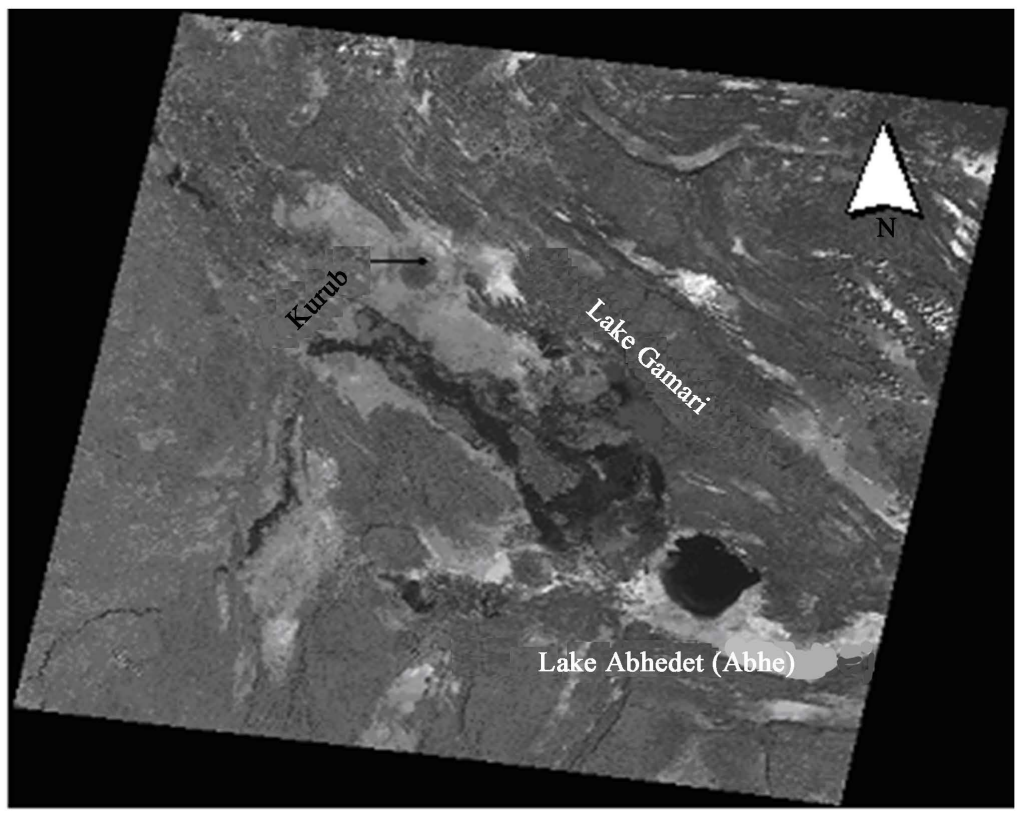

Figure 7. Landsat $7 \mathrm{ETM}^{+}$imagery of the study area (Band 1).

It is observed that most parts of the study area are covered by alluvial and lacustrine deposits with some lava flows, volcanic cones such as Kurub. Thick lava flow exposed near Semera area shows horizontal contacts between flow units and columnar joints which could be open or partially infilled with sediments. The main drainage system of the Awash River is controlled by these NW-SE striking geological structures. Most of the faults are covered by thick alluvial deposits. These linear structures along the NW-SE direction clearly shows the red sea trends and indicates the relevance of tectonics for groundwater and surface water potential in the area.

Most lineaments indicate areas where underlying bedrock is more fractured (Figure 8 and Figure 9), hence higher in local permeability and allowing groundwater to move more easily towards water well. The fracturing and permeability increases near the lineaments. From Landsat $\mathrm{ETM}^{+}$image structures in the Graben are identified by their variations in surface reflectance. As we can observe from the water wells and geothermal wells data drilled in the area and analysis based on the Landsat data almost all lineaments observed in the area have hydrological and hydrogeological significance.

The Awash River changes its trend when it has just reached the Tendaho Graben (Figure 10). Open fractures which contribute for the recharge and circulation of groundwater are important structures in the Graben. Both from the satellite image and field checking these structures are clearly observed especially in the Manda Hararo area (Figure 8). The tensional open fractures are the most promising for the storage and transmission of groundwater [12]. Significant quantities of freshwater of the area which are recharged from the western highlands and local precipitation are lost to the sea through the major deep seated open fractures. 

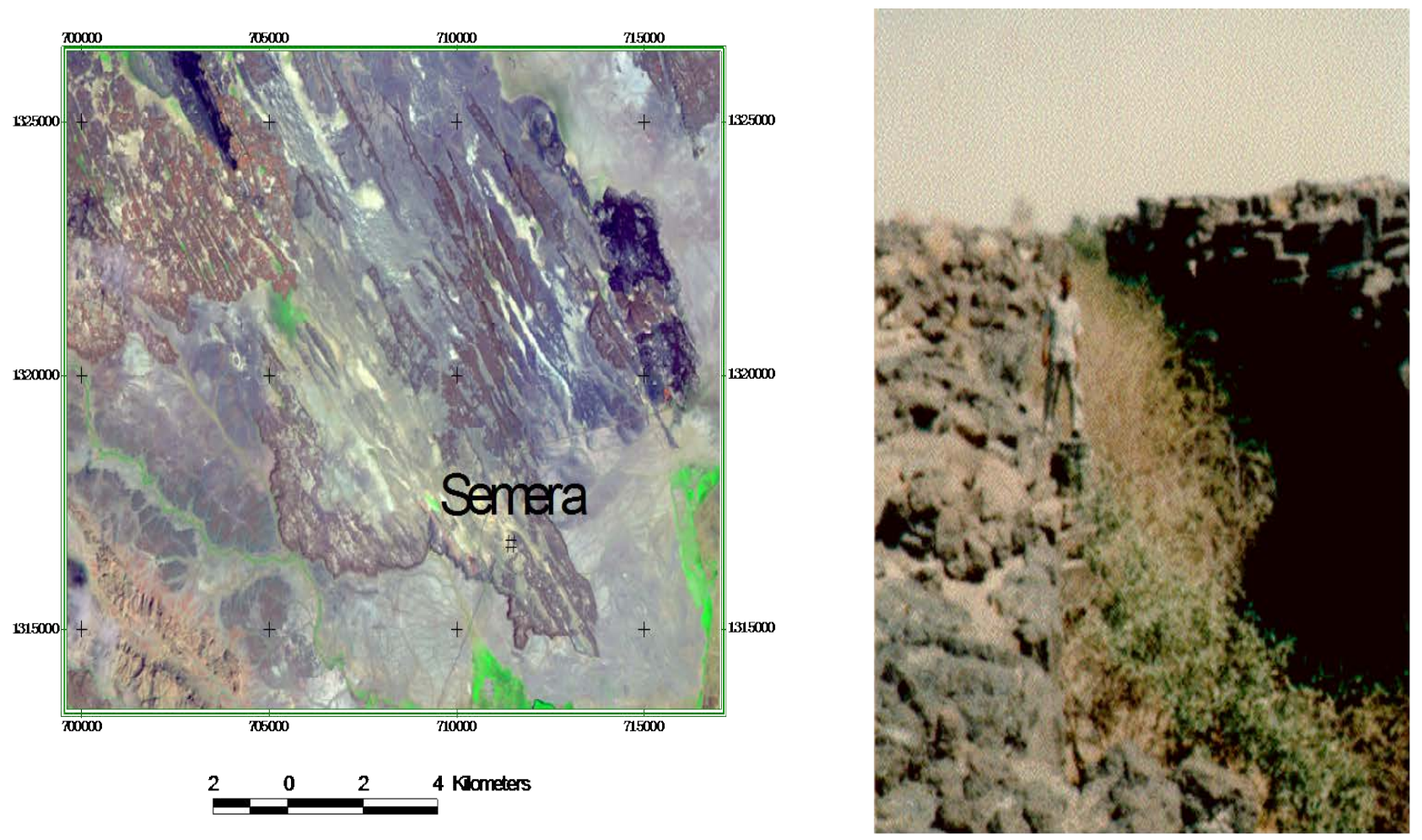

Figure 8. North western part of the Tendaho Graben near Semera area (the green portion is Awash river course) and one of the open fractures in Manda Hararo.

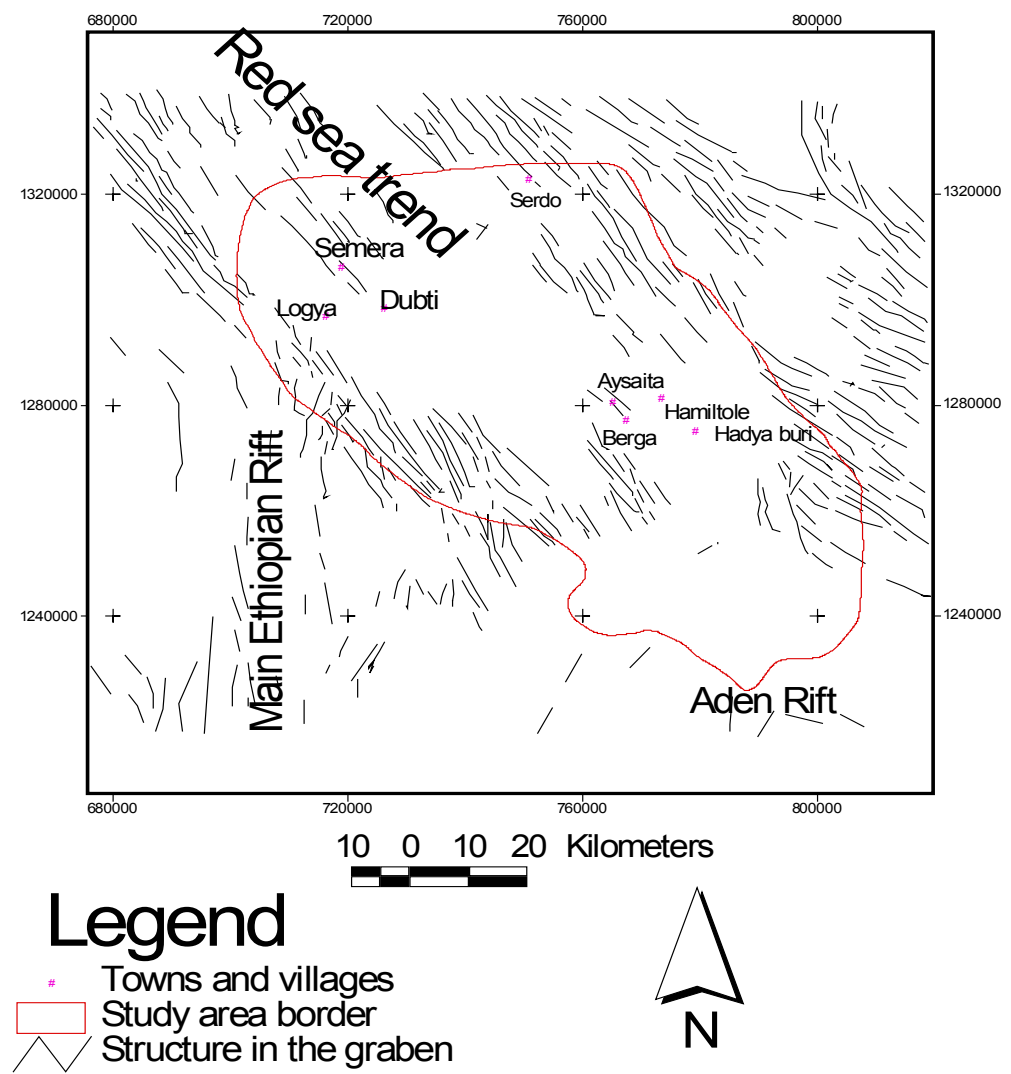

Figure 9. Tectonic structure of the study area (extracted from Landsat $\mathrm{ETM}^{+}$). 


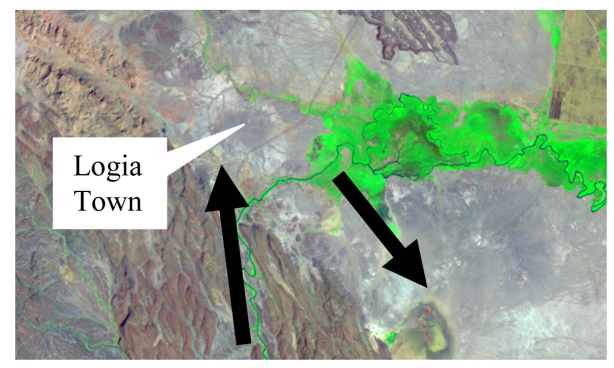

Figure 10. The Awash River course change due to the red sea trend tectonic structures.

Tectonic structures are groundwater conduits and barriers of the subsurface water flow. The fault system of the Gamari, south east boundary of the Graben and some volcanic mountains like Dama'ale act as a barrier both for Awash River and the groundwater system and are responsible for the formation of Lake Afambo, Lake Gamari, Lake Adobed, Lake Abhedet (Abhe) and other small lakes and swampy area. Here the high groundwater residence time together with the hot climate of the area contribute for the high TDS and water quality deterioration of the shallow aquifers. The axial part of the Graben characterized by abundance of open fractures in the Afar stratoid series. In the plain of Tendaho Graben these structures dominantly covered by thick alluvial deposits.

Vegetation indices (VI) are combinations of reflectance of two or more bands, usually in the visible red band and the near infrared band. Normalized difference Vegetation index (NDVI) is a vegetation index that calculates how far a pixel plots from the soil line, using the relationship:

$$
\mathrm{NDVI}=\left(\mathrm{DN}_{\mathrm{NIR}}-\mathrm{DN}_{\mathrm{RED}}\right) /\left(\mathrm{DN}_{\mathrm{NIR}}+\mathrm{DN}_{\mathrm{RED}}\right)
$$

where DN = Digital number after haze correction, NIR $=$ Near Infrared.

Its values vary between -1 and +1 . Negative or low values are indicates water, bare soil, clouds or low green vegetation density. Highly vegetated area show higher NDVI value. According to the Holben, cited [13], calculation of average NDVI values from AVHRR channel1 and 2 for a range of different covers type (Table 5), large parts of the Graben are bare soil. The vegetated parts are medium green leaf.

The NDVI image of the area shows that the vegetation density is higher along the Awash River and at its terminal environs. The NDVI obtained from the NOAA image for the study area shows that the value ranges between 0.05 and 0.26 (Figure 11). NDVI values vary seasonally due to rainfall and runoff variation both within the Graben and the upper course of the Awash River. The NDVI values for the years 1986-2000 shows that vegetation density increase in November and October. These vegetation densities are mainly along the Awash River and its flood plains and Marshy Area of the Graben. The maximum NDVI value in October 1996 indicates the maximum green vegetation activity due to both ecology and weather factors.

The existence of palm trees near Afambo and its surrounding localities is good indicator of shallow groundwater potential. Plants typical of a wetland like the 


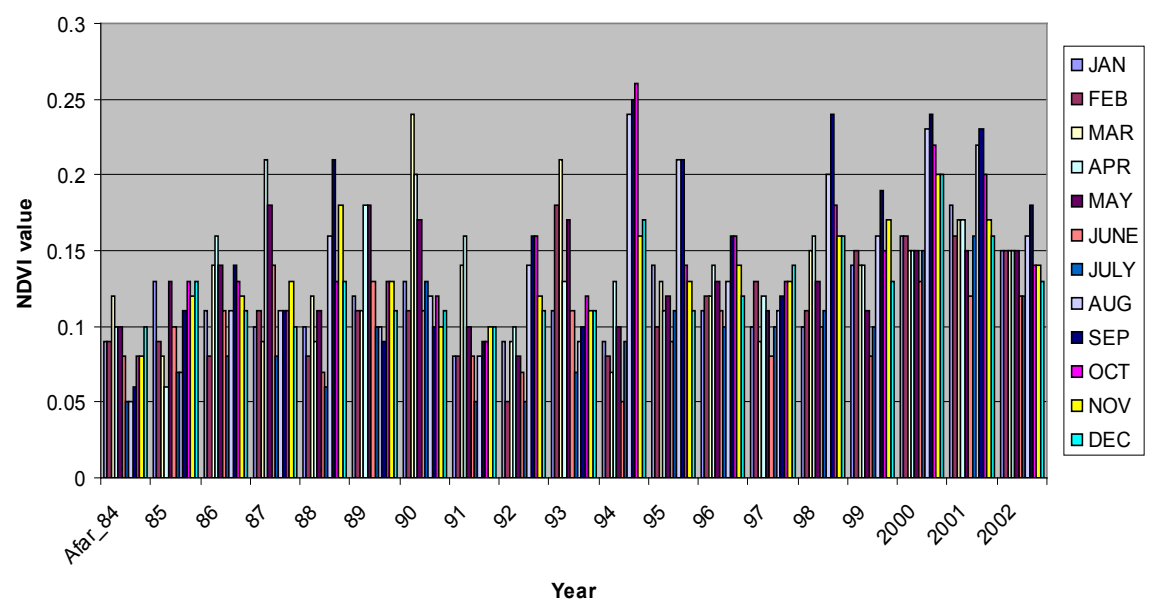

Figure 11. NDVI values calculated from NOAA satellite image data.

Table 5. NDVI values for different cover types as measured from NOAA-7 (After Holben 1986 cited in Meijerink et al. 1994).

\begin{tabular}{cccc}
\hline \multirow{2}{*}{ COVER TYPE } & \multicolumn{3}{c}{ PLANETARY ALBEDO } \\
\cline { 2 - 4 } & Channel 1 & Channel 2 & NDVI \\
\hline Dense green-leaf vegetation & 0.050 & 0.150 & 0.500 \\
Medium green leaf vegetation & 0.080 & 0.110 & 0.140 \\
Light green leaf vegetation & 0.100 & 0.120 & 0.090 \\
Bare soil & 0.269 & 0.283 & 0.025 \\
Clouds (opaque) & 0.227 & 0.228 & 0.002 \\
Snow and ice & 0.375 & 0.0342 & -0.046 \\
Water & 0.022 & 0.013 & -0.257 \\
\hline
\end{tabular}

terminal lake environs of the Tendaho Graben environment would suggest that groundwater is near the surface. Phreatophytes may directly respond to groundwater availability and quality.

Since the studied area is characterized by low rainfall and high temperature, large parts are sparsely vegetated or bare land. The presence of vegetation usually indicates the presence of surface or shallow or deep groundwater depending on the type of vegetation cover. The NDVI image which has been derived from band 4 and band 3 of the Landsat $\mathrm{ETM}^{+}$image and the false color composite of different bands have shown that most of the vegetation cover is found along the Awash River left and right banks and marshy area of the Graben.

Based on the analysis made from the Landsat $\mathrm{ETM}^{+}$data, existing borehole hydraulic data and ground truthing the hydrostratigraphic units of the Graben are classified in to five major classes. These are alluvial deposits, lacustrine deposits, Scoriaceous basalt/scoria, fractured basalts and Rhyolite. The flow of water in the rock is largely determined by the distribution of interconnected fractures and the way in which their apertures respond to the associated stress field [14]. The aquifer system in Aysaita and its surrounding area is mainly scoriaceous 
basalt, scoria and fractured basalt which yield better than granular sediments of the Graben.

The pumping test results of the water well drilled in Adadali area near Aysaita yields extremely high. The tectonic structures are regional and extend to a great distance from which they transport huge amount of water to the great depth of the Graben groundwater system. Awash River also loses water when it flows in the highly permeable sediments of the Tendaho plains.

The regional groundwater flow is from the escarpments into the valley and northeastwards to Lake Abe $(243 \mathrm{~m}$ amsl) and possibly further to the Danakil Depression [14] in the far northern part of the Graben. Both the surface and groundwater flowing within Tendaho come from the western Ethiopian rift escarpment, from altitudes above $1500-1700 \mathrm{~m}$ a.m.s.l characterized by heavy annual rainfall, positive rainfall/evapotranspiration ratio. The main discharge area of the graben is the Awash River plains of Logya, Dubti and Aysaita. Aysaita area which is situated on a series of north-west trending closely set parallel extension faults is one of groundwater discharging areas (Figure 12). Due to these structures which form a number of parallel ridges in and around Aysaita and the high water bearing capacity of the scoriaceous basalt the area is categorized as a high groundwater potential area.

According to previous studies the bulk of the groundwater flow through the western plateau escarpments passes in to the Afar plains [14] but much of the water flows to the red sea.

Due to the high temperature and low rainfall there is less recharge from precipitation or is not in a considerable amount to the aquifer system. From the analysis of existing discharge records in Dubti and Aysaita stations the discharge of the Awash River decreases down to the terminal lake area due to lose of water to the groundwater system of the area. From the Awash River bed and banks large amounts of water infiltrate in to the alluvial sediments from the entry of Tendaho Graben up to Afambo area.
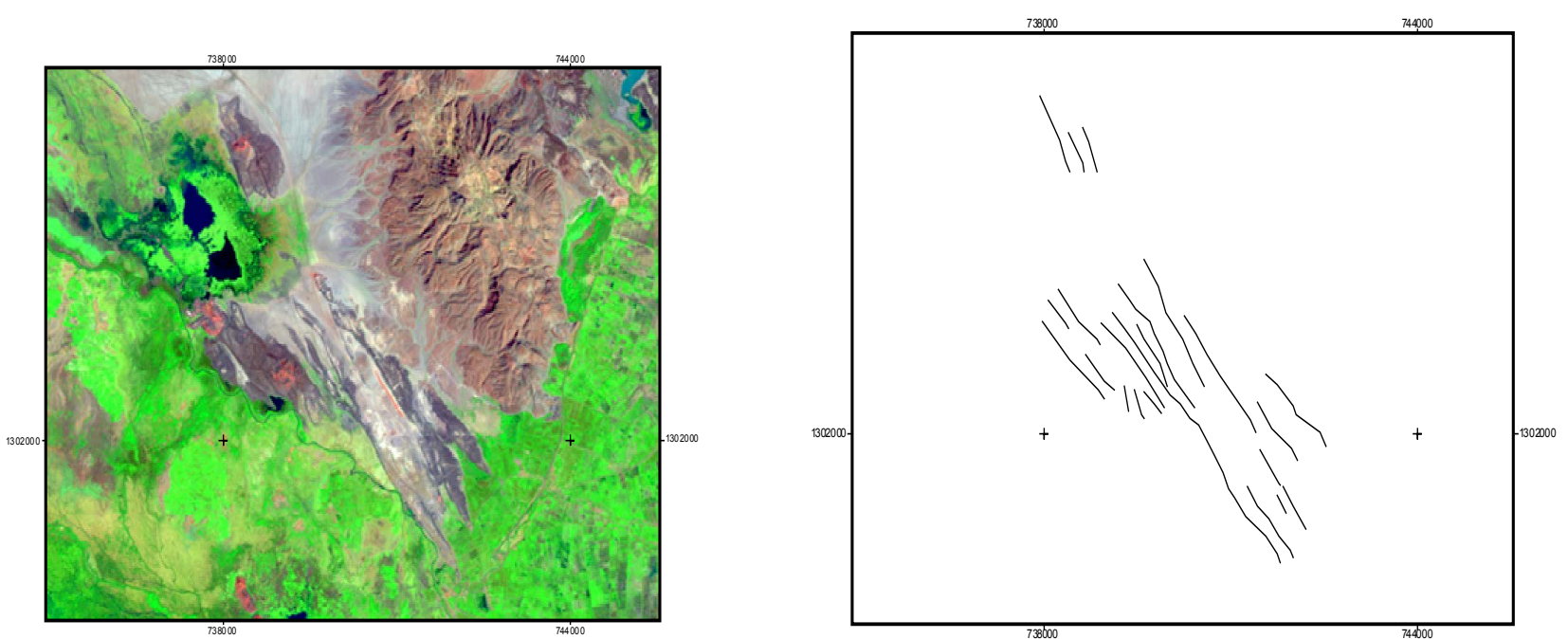

Figure 12. NW-SE trending parallel extension faults around Aysaita control the groundwater flow and occurrence. 


\section{Conclusions}

In this study it is found that tectonic structures have great roles in controlling hydrological and hydrogeological characteristics of the Graben. The tectonic structures especially the NW-SE (Red sea trend) are the major controlling feature in surface and groundwater resources characteristics. The Awash River course change, the formation of lakes and swamps, discharge of huge amount of water in Aysaita area and existence of some geothermal surface manifestation like Alalobad and surface manifestation of springs are the main output of the tectonic structures. Recharges to the groundwater system of the Graben are from two main sources: Awash River and the NW-SW trending tectonic structures. Remote sensing has invaluable capability in groundwater and surface water assessment of an area like this Graben where there is accessibility problem and challenging hot climatic conditions which hinders ground investigations. Since there is no dense vegetation cover tectonic structures and lithology clearly identified without applying sophisticated image processing works.

Hydrogeological and geological maps derived from Landsat $\mathrm{ETM}^{+}$and field check have shown that the Graben is predominantly covered by thick unconsolidated sediments with medium to high groundwater bearing capability. The false color composite (FCC) of Band 7, Band 4 and Band 1 in RGB order respectively has shown that almost all the Graben floor except some volcanoes is composed of unconsolidated sediments of alluvial, lacustrine and Aeolian deposits.

\section{Acknowledgements}

We would like to forward our sincere thanks to Fitsume Yemenu, University of New England (Australia) and Desalegn Terecha (Holistic consulting) for their encouragement to publish this article.

\section{References}

[1] Jensen, J.R. (1986) Remote Sensing and the Environment. Prentice-Hall, Upper Saddle River.

[2] Seelan, S.K and Thiruvengadachari, S. (1981) Satellite Sensing for Extraction of Groundwater Resources Information. Proceedings of the Fifteenth International Symposium on Remote Sensing of Environment, Ann Arbor, 11-15 May 1981, 509-518.

[3] Curran, P.J. (1996) Principles of Remote Sensing. Longman, London, 247 p.

[4] EPA (1998) Background Information on Drought and Desertification in Ethiopia. Environmental Protection Authority, Addis Ababa, 9 p.

[5] Souriot, T. and Brun, J.P. (1992) Faulting and Block Rotation in the Afar Triangle, East Africa: The Danakil Crank Model. Geology, 20, 911-914. https://doi.org/10.1130/0091-7613(1992)020<0911:FABRIT>2.3.CO;2

[6] Tapponnier, P., Armijo, R., Manighetti, I. and Courtillot V. (1990) Bookshelf Faulting and Horizontal Block Rotations between Overlapping Rifts in Southern Afar. Geophysical Research Letters, 17, 1-4. https://doi.org/10.1029/GL017i001p00001

[7] Gibson, I.L. (1970) The Structure of Afar and the Northern Part of the Ethiopian 
Rift. Philosophical Transactions of the Royal Society of London: Series A, 267, 331-338. https://doi.org/10.1098/rsta.1970.0039

[8] Schaefer, H.U. (1975) Investigations on Crustal Spreading in Southern and Central Afar (Ethiopia). Proceedings of the First Symposium on the Afar Region and Related Rift Problems, Bad Bergzabern, 1974, 289.

[9] Tendaho, A. (1996) Geothermal Project, Final Project, Addis Ababa, Ethiopia.

[10] Drury, S.A. (1993) Image Interpretation in Geology. 2nd Edition, Chapman and Hall, New York, 262 p.

[11] Korme, T. (1999) Lithological and Structural Mapping of the Northeast Lake Ziway Area, Ethiopian Rift, with the Help of Landsat TM Data. SINET: Ethiopian Journal of Science, 22, 151-174.

[12] FAO (1999) Groundwater Exploration, Pilot Study in the Syrian Arab Republic, Remote Sensing for Decision Makers, Rome, Italy. http://www.fao.org/sd/EIdirect/Elre0070.htm

[13] Meijerink, A.M.J, Brouwe, H.A.M, Mannaerts, M.C. and Valenzuela, C. (1994) Introduction to the Use of Geographic Information Systems. ITC, Enschede.

[14] Halcrow (1989) Master Plan for the Development of Surface Water Resources in the Awash Basin, Final Report Vol.5, Annex C: Assessment of Groundwater Potential. 